\title{
A CRIANÇA SURDA: REFLEXÕES SOBRE O PROCESSO DE ALFABETIZAÇÃO E LETRAMENTO EM SALAS BILÍNGUES*
}

Wilma Pastor de Andrade Sousa

\section{Introdução}

O processo de alfabetização e letramento de crianças tem sido discutido em nosso país e no mundo nas últimas décadas. Pesquisadores de diversas áreas como a Psicologia e a Pedagogia, por exemplo, têm se empenhado em apontar estratégias que possam não apenas nortear os professores alfabetizadores, mas também facilitar a apropriação da escrita por parte das crianças. Dentre esses recursos, facilmente podemos encontrar hoje materiais diversos, com estratégias didático-metodológicas que têm o som como grande aliado. Destacamos, por exemplo: parlendas, rimas, aliterações, trava línguas, jogos e músicas destinados as crianças que se encontram em pleno desenvolvimento da alfabetização e letramento. Entretanto, constatamos em diversas pesquisas, como nos mostra Fernandes (2006), que esses recursos auxiliam a criança ouvinte a se apropriar do Sistema de Escrita Alfabético - SEA, mas em relação à criança surda, essas estratégias, pautadas no som, têm resultado em implicações desfavoráveis para esse público de estudantes, os quais, devido ao impedimento auditivo, não têm o som como base para o aprendizado da escrita.

Nesse sentido, de acordo com Fernandes (2006), um procedimento de alfabetização em que são destacadas as sílabas iniciais ou finais das palavras, objetivando a constituição da consciência fonológica, não faz sentido para o estudante surdo, já que, para ele, a palavra é percebida em suas propriedades visuais e não auditivas, logo, a sílaba não é percebida. Isso nos faz refletir sobre as dificuldades encontradas pelos professores alfabetizadores em ensinar uma língua alfabética sem lançar mão das estratégias sonoras, como também pelos estudantes surdos em se apropriarem da escrita de uma língua oral auditiva, a exemplo da nossa Língua Portuguesa.

*DOI - 10.29388/978-65-86678-60-4-0-f.383-400 
Nessa direção, muitas são as nossas inquietações a esse respeito, como, por exemplo: quais são as principais dificuldades enfrentadas pelas professoras das salas regulares bilíngues? Qual é a concepção das professoras sobre o processo de alfabetização e letramento das crianças nessas salas? Como é a dinâmica durante as aulas nessas salas? Partindo desses questionamentos, o objetivo principal deste texto é discutir o processo de alfabetização e letramento em salas bilíngues para surdos, com base em uma investigação realizada em salas regulares bilíngues para surdos, em escolas da rede municipal na cidade de Recife-PE. Temos como objetivos específicos: a) descrever os principais obstáculos enfrentados pelos professores alfabetizadores para trabalhar nas salas regulares bilíngues; b)identificar qual é a concepção dos professores acerca do processo de alfabetização e letramento das crianças nessas salas; c) analisar a dinâmica dessas salas.

\section{Salas bilíngues para surdos: expectativa da efetivação de uma educação bilíngue}

Na condição de militante na comunidade surda, somos testemunha da luta de anos por direitos linguísticos e sociais, bem como por acesso a uma educação que respeite as peculiaridades do estudante surdo, a exemplo da educação bilíngue. Nesse sentido:

O bilinguismo não só respeita a língua dos sujeitos surdos, como também considera outros aspectos que influenciam diretamente na educação desses sujeitos, como a construção de uma identidade saudável e uma cultura pautada na língua em uso, promovendo um ambiente educacional e um ensino-aprendizagem acessíveis e com melhores condições (SOUSA, 2014, 38 e 39).

Nessa direção, vivenciamos a luta incessante das pessoas surdas pela garantia de uma educação bilíngue que não se restrinja ao uso apenas de duas línguas, a língua de sinais como primeira língua (L1) e a língua majoritária do país como segunda língua (L2), mas que Ihes assegurem, desde a educação infantil, o acesso a L1 e a L2, sendo esta na modalidade escrita, em um ambiente em que circule a cultura surda e que propicie a esses sujeitos a construção de uma identidade genuína, a partir do contato com os seus pares e adultos surdos. 
Desde o reconhecimento da Língua Brasileira de Sinais - Libras, por meio da Lei no 10.436, de 24 de abril de 2002, e do Decreto no 5.626, de 22 de dezembro de 2005, a conquista por uma educação bilíngue para surdos tornou-se mais perto de se concretizar. Contudo, foi com a Meta 4.7 do Plano Nacional de Educação PNE 2014-2024que tivemos um avanço significativo e mais concreto dessa discussão. Com base nesses documentos citados, foram criadas cerca de 7 salas regulares bilíngues de alfabetização para surdos em escolas da rede municipal de ensino da cidade do Recife-PE. Essas salas foram instituídas por meio do Decreto no. 28587, de 11 de fevereiro de 2015, e, posteriormente, normatizadas através da Instrução Normativa no2, de 12 de janeiro de 2016. É importante registrar que o decreto que instituiu essas salas teve, na sua construção, a participação de representantes da comunidade surda, fazendo valer a conhecida máxima "nada sobre nós sem nós".

Essas conquistas representaram um passo importante para as pessoas surdas, gerando grande expectativa de termos, efetivamente, uma educação bilíngue cujas especificidades linguísticas e culturais dessas pessoas fossem respeitadas desde o início da sua escolaridade. Entendemos que esse início deve ocorrer o mais cedo possível, com o acesso garantido desses sujeitos a Educação Infantil, considerada como primeira etapa da educação básica. Essa etapa é organizada em creche (atendimento entre 0 e 3 anos e 11 meses) e pré-escolas (atendimentos entre 4 e 5 anos e 11 meses).

Segundo Cabral (2005), a Educação Infantil ganhou maior importância depois da promulgação da Constituição Federal de 1988 e da vigência da Lei de Diretrizes e Bases da Educação Nacional-LDBEN, Lei no 9394/96. Apenas a partir de então, a criança começou a ser reconhecida como sujeito de direitos e sua educação passou a ser considerada como nível de ensino. Há, portanto, a expectativa de que, para as crianças surdas, a vivência de uma educação bilíngue na creche será não apenas o primeiro espaço institucional, mas o lócus que proporcionará o contato com falantes fluentes da língua de sinais, já que mais de $90 \%$ dessas crianças são filhas de pais ouvintes.

O Decreto que criou as salas regulares bilíngues para estudantes surdos em Recife, no 28.587 de 11/02/2015, traz em seu texto:

§ 3o As salas regulares bilíngues, referidas no caput deste artigo, são para atender às etapas da educação infantil, do ensino fundamental regular e da modalidade de educação de jovens e adultos. 
$\S$ 4 Na etapa da educação infantil, as salas são para atender crianças da faixa etária de 4 (quatro) a 5 (cinco) anos, desde que apresentem estrutura adequada para esse atendimento.

§ 5o Quanto aos estudantes de 0 (zero) a 3 (três) anos, quando detectados, serão encaminhados aos professores do Atendimento Educacional Especializado (AEE) para a educação precoce, cujo objetivo será, através de recursos pedagógicos apropriados, oferecer espaço à criança para o conhecimento, estabelecendo relações no mundo que o cerca, sendo respeitadas suas especificidades de desenvolvimento.

De acordo com esse decreto, apesar de essas salas terem o objetivo de proporcionar o acesso às pessoas surdas desde a Educação Infantil, essa realidade só será possível a partir da pré-escola. A garantia desse "atendimento" será apenas para crianças que se encontram na faixa etária de 4 a 5 anos, isso condicionada, ainda, a uma estrutura adequada para esse atendimento. É importante destacar que o decreto não deixa claro que estrutura é essa, levando a várias interpretações, ou seja, caso a instituição de ensino entenda que não dispõe dessa estrutura, a escola e, consequentemente, o município, ficam isentos de oferecerem essa etapa de ensino que para nós é crucial para qualquer criança.

Nesse sentido, em pesquisa realizada por Sousa (2015) nas creches municipais do Recife, com o objetivo de discutir as práticas pedagógicas propiciadoras da inclusão da criança surda, participaram 17 professores, sendo que a maioria dos participantes, $71 \%$ (setenta e um por cento), relataram nunca terem tido experiência com estudantes surdos, apesar de 7, dos 17 participantes, lecionarem em creches há mais de 10 anos. Esse dado nos mostra como essa realidade tem trazido consequências graves no processo de alfabetização e letramento das crianças surdas. Ao refletirmos sobre essa questão, temos clareza de que a falta de oferta de educação para aquelas crianças que têm abaixo de quatro anos resulta em grande prejuízo e atraso. Essas implicações têm sido verificadas nas tentativas fracassadas de professores em alfabetizar essas crianças que chegam à escola sem conhecimento de mundo e sem domínio de uma língua, exceto aquelas filhas de pais surdos que correspondem a um percentual mínimo.

É importante ressaltar que cada faixa etária demanda cuidados e aprendizagens peculiares ao período em que a criança se encontra. A esse 
respeito, a Base Nacional Comum Curricular - BNCC (BRASIL, 2017) considera as diferenças no ritmo de aprendizagem e desenvolvimento de cada criança, bem como reconhece as especificidades inerentes aos diferentes grupos que compõe a etapa da Educação Infantil. Assim, os objetivos de aprendizagem e desenvolvimentos estão organizados na BNCC (BRASIL, 2017) em 3 grupos distintos, considerando a idade de cada criança. Temos 2 grupos na creche: os bebês (entre 0 e 1 ano e 6 meses) e as crianças bem pequenas (entre 1 ano e 7 meses e 3 anos e 11 meses); e 1 grupo na pré-escola: as crianças pequenas (entre 4 anos e 5 anos e 11 meses).

Com base no decreto que instituiu as salas regulares bilíngues em Recife, bem como, considerando a distribuição da BNCC (2017) anteriormente mencionada, apenas as crianças surdas pequenas poderão ter acesso a essas salas, ficando a educação dos bebês e das crianças bem pequenas delegada ao Atendimento Educacional Especializado (AEE). Logo, essa organização não condiz com o material publicado pelo Ministério da Educação e Cultura, intitulado Educação Infantil: Saberes e práticas da inclusão: dificuldade de comunicação e sinalização - Surdez (BRASIL, 2006), o qual traz vários esclarecimentos sobre as crianças surdas e, principalmente, orientações e encaminhamentos sobre a educação dessas crianças na Educação Infantil, tanto em creches quanto em pré-escolas:

Assim como para as demais crianças, o ideal é que a criança surda, na faixa etária do nascimento aos três anos, frequente creches e conte com a presença de um professor para o ensino de língua portuguesa e de um professor/instrutor surdo (para que ela tenha contato diário com a Libras), além de outros profissionais (BRASIL, 2006, p. 44 grifo nosso).

Destacamos a ênfase que demos a faixa etária em que a criança surda deverá ter acesso na Educação Infantil e a importância da presença de um adulto surdo falante da Libras para que, desde muito cedo, essa criança tenha contato com alguém com as mesmas peculiaridades linguísticas e culturais suas, já que geralmente elas estão inseridas em famílias de ouvintes que não sabem língua de sinais e que não lhes consideram diferente linguisticamente, mas "deficientes". Isso não interfere apenas no atraso da linguagem, o que já é uma perda significativa, mas poderá desencadear um processo de autoestima baixa, assim como uma construção de identidade deficitária, trazendo drásticas consequências psicológicas. A esse respeito, de acordo com Kober 
(2008), é essencial considerar o acesso à língua de sinais pela criança surda o mais cedo possível, oferecendo a ela uma vivência com surdos usuários dessa língua, seus pares linguísticos. O contato com a língua de sinais e a cultura surda desde bebê, certamente evitará um distanciamento dos padrões do desenvolvimento socioafetivo, cognitivo e de linguagem, possibilitando a essas crianças um pleno desenvolvimento. Trata-se, portanto, de uma questão de equidade.

Nessa direção, ao resgatarmos os Parâmetros Curriculares Nacionais da Educação Infantil (1998), constatamos que eles trazem alguns objetivos para a prática docente no sentido de que as crianças desenvolvam várias capacidades, dentre elas: a) desenvolver uma imagem positiva de si, atuando de forma cada vez mais independente, com confiança em suas capacidades e percepção de suas limitações; b) estabelecer vínculos afetivos e de troca com adultos e crianças, fortalecendo sua autoestima e ampliando gradativamente suas possibilidades de comunicação e interação social. Entretanto, provavelmente esses objetivos serão atingidos apenas se a criança surda tiver a oportunidade de vivenciar uma educação bilíngue que considere as suas peculiaridades linguísticas e culturais. Acontecendo isso, acreditamos que o processo de alfabetização e letramento será menos traumático tanto para o professor alfabetizador como para a criança surda. Infelizmente, ainda não é essa a realidade vivida em grande parte do nosso país. É sobre essa questão que discutiremos a seguir.

\section{Alfabetização e letramento para surdos}

Em geral, a criança surda inicia o processo de alfabetização com grande defasagem se comparada à criança ouvinte. Além de não falar a língua que está aprendendo a escrever, a maioria delas também não domina ainda a língua de sinais. Nesse contexto, ao ressaltar a importância da língua de sinais para essas crianças, como base para o aprendizado da Língua Portuguesa como segunda língua, Fernandes (2006, p. 14) afirma que "sem a sua mediação, os alunos não poderão compreender as relações textuais na segunda língua, já que necessitam perceber o que é igual e o que é diferente entre sua primeira língua e a língua que estão aprendendo.".

Nesse sentido, um dos motivos que nos leva a defender que essas crianças surdas tenham a garantia de acesso à língua de sinais antes de 
iniciarem o processo de alfabetização é exatamente o papel mediador exercido pela língua de sinais na aprendizagem de uma segunda língua. Assim, elas poderão identificar as diferenças entre a sua língua e a Língua Portuguesa escrita. A partir de então, acreditamos que será possível estabelecer formas de compreensão por meio de estratégias criadas pelos professores alfabetizadores, como tentativa para que elas reconheçam essas diferenças entre as duas línguas - a língua falada por elas e a língua alvo -. A esse respeito, segundo Santos, Silva e Sousa (2013) quando a criança adquire o domínio da língua de sinais, esta auxiliará no processo de apropriação da escrita, já que a criança cria uma imagem da palavra escrita em Língua Portuguesa, tendo como parâmetro o sinal que já conhece na sua primeira língua, a Libras.

Corroborando essa ideia, Quadros e Schmiedt (2006) propõem o ensino da Língua Portuguesa para a criança surda por meio de estratégias que possibilitem que ela encontre sentido e correspondência com algo do seu universo de conhecimento, uma vez que ela parte da L1 para a L2, estabelecendo uma relação simbólica com o seu significado. Portanto, além de a língua de sinais ter o papel de mediar a aprendizagem da $L 2$, ela serve de base para o letramento das crianças surdas. Paulatinamente elas vão adquirindo experiências e entendendo o sentido da língua nos diferentes contextos existentes das práticas sociais.

A imersão na língua de sinais, o contato com seus pares e com adultos fluentes em Libras, provavelmente, possibilitarão que a criança surda utilize a língua com propriedade e atribua significado à escrita, deixando para trás o rótulo de copista que lhes foi atribuído durante anos e permanece até os dias de hoje.

Concordamos com Dechandt (2006, p.292) ao afirmar que: “[...] a apropriação de uma segunda língua (L2) é um processo, constituído por etapas que se sucedem no tempo, cujo ponto de partida é a Libras e o ponto de chegada é a escrita do Português.". Essa afirmação confirma ainda mais o importante papel que a língua de sinais tem no processo de alfabetização e letramento da criança surda, embora seja uma língua com estrutura diferente daquela que ela está aprendendo a escrever. Contudo, a apropriação de um sistema de escrita não acontece em um passo de mágica, trata-se de um processo complexo para qualquer criança, sobretudo para a criança surda que se vê diante de uma língua alfabética, sendo ela usuária de uma língua espaçovisual - a língua de sinais -. 


\section{Metodologia}

Este estudo foi realizado em 04 (quatro) salas regulares bilíngues de 03 (três) escolas públicas da rede municipal de ensino, da cidade de Recife. Participaram desta pesquisa 04 (três) professoras ouvintes bilíngues.

Por questões éticas, as participantes serão chamadas de P1, P2, P3 e P4 respectivamente, preservando-se as suas identidades. Em relação às salas, iremos nos referir como S1, S2, S3 e S4, além de " $\mathrm{S}$ " para as respostas afirmativas e "N" para as negativas. Esclarecemos que o número atribuído a cada sala de aula corresponde ao número utilizado para nos referirmos a cada voluntária participante. Os recortes de fala dos participantes serão apresentados em itálico, com destaque em negrito para os trechos enfatizados na análise.

De posse da carta de anuência, e após a concordância em participar voluntariamente deste estudo, as participantes assinaram um Termo de Consentimento Livre e Esclarecido- TCLE. A seleção das voluntárias foi feita dentro do universo total de cada contexto institucional, tendo sido estabelecido como critério de inclusão, professores efetivos de salas bilíngues para surdos, que ensinam em turmas de alfabetização. Como critérios de exclusão não foram selecionados os professores substitutos e os que não trabalham com salas bilíngues para surdos, já que não se enquadravam no foco deste estudo.

Os dados foram coletados em dois momentos: no primeiro, por meio de entrevista semiestruturada, previamente agendada com as voluntárias, no horário do intervalo; no segundo, através de 04 observações feitas em cada sala de aula dos voluntários participantes, as quais foram registradas em um diário etnográfico. Para viabilizar as observações, organizamos previamente um quadro alinhado com os objetivos da pesquisa. Em relação à análise de dados, esta ocorreu baseada na perspectiva da análise de conteúdo orientada por Bardin (2016).

\section{Resultados e Discussão}

Apresentaremos a seguir os resultados e discussão com base na entrevista semiestruturada feita com as professoras voluntárias participantes deste estudo, bem como as observações realizadas em sala de aula. Para isso, 
as respostas das entrevistas foram organizadas por categorias, a saber: 1) obstáculos enfrentados pelos professores alfabetizadores para trabalhar nas salas regulares bilíngues; 2) concepção dos professores sobre o processo de alfabetização e letramento nas salas regulares bilíngues. Em relação aos resultados das observações, optamos em apresentá-los por meio de um quadro contendo a dinâmica das salas regulares bilíngues para surdos. Objetivando maior clareza em relação aos dados, as respostas das participantes serão apresentadas em itálico, conforme já mencionado na metodologia, com destaque em negrito para trechos de fala a serem discutidos na análise.

\section{Obstáculos enfrentados pelos professores alfabetizadores para trabalhar nas salas regulares bilíngues.}

P1. A falta de conhecimento da criança e da família sobre a Libras é a principal dificuldade. Além disso, percebo que uma criança tem muita vergonha de usar a Libras na frente de outras pessoas. Ela hoje está com 6 anos e é o primeiro ano que tem contato com a língua de sinais.

$P 2$. A maior dificuldade é devido à escassez de material didático direcionado à educação bilíngue ou educação de surdos e a pouca formação continuada P3. A estrutura física da escola, a falta de materiais acessíveise a necessidade de adequação do material existente.

P4. A falta de conhecimento da Libras por parte das crianças que, muitas vezes, aprendem a língua na escola e material para trabalhar com as crianças.

Dentre as respostas das participantes, destacamos a falta de conhecimento da Libras pela criança surda, mencionada por P1 e P4. Evidenciamos com isso que, embora a oferta das salas bilíngues tenha sido feita, a questão da alfabetização e do letramento do estudante surdo parece ainda estar distante de ser resolvida. Conforme discutimos anteriormente neste texto, apesar de a etapa da Educação Infantil ter sido contemplada no Decreto $n$ ㅇ $28.587 / 2015$ como garantia de ser ofertada, não se considerou as etapas iniciais que são cruciais no desenvolvimento infantil. Como resultado, temos acompanhado a angústia dos professores alfabetizadores dessas salas, assim como o esforço das crianças surdas que se encontram em processo de alfabetização. 
É estranho, mas compreensível, quando P1 relata que uma das crianças da sua sala tem vergonha de usar a Libras. Isso é estranho porque a Libras é adquirida no contato com os falantes de forma natural, já que é uma língua totalmente acessível para as pessoas surdas. Uma língua que thes possibilita se colocar como sujeito, como ser pensante. Compreensível porque, conforme relatado por P1, essa criança só teve contato com a Libras aos 6 anos. Essa realidade nos mostra claramente as implicações quando a criança deixa de ter acesso à sua língua desde o nascimento. Além de nos mostrar também a importância do contato com falantes fluentes da sua língua, com seus pares e surdos adultos, para que a criança se constitua como sujeito e desenvolva uma identidade saudável.

A escassez de material acessível em Libras para o professor trabalhar com as crianças surdas foi predominante nas respostas uma vez que P1, P3 e P4 relataram esse aspecto como um obstáculo encontrado ao se trabalhar nas salas regulares bilíngues para surdos. Esses dados nos mostram, portanto, a necessidade não apenas de aquisição de materiais acessíveis, mas também de formação continuada sistemática que possibilite aos professores pensarem nos princípios que norteiam a educação bilíngue para surdos e suas peculiaridades, permitindo-Ihes mais autonomia para fazer adequações em materiais já existentes ou criar novos materiais. Apesar de "a pouca formação continuada" ter sido mencionada apenas por P2, essa reclamação tem sido observada nas falas das professoras dessas salas em conversa informal.

\section{Concepção dos professores sobre o processo de alfabetização e letramento nas salas regulares bilíngues}

P1. Acredito que acontece da "mesma forma" que acontece com os ouvintes. Nós trabalhamos textos, vídeos que tenham um contexto, para depois ensinar a língua portuguesa escrita. Nós ensinamos primeiramente a Libras, dentro dos diversos contextos e depois o Português escrito.

P2. Penso que acontece ensinando-lhes primeiro o concreto e o abstrato através de sua língua materna, a Libras.

P3. Para alfabetizar surdos precisamos "desconstruir" o que sabemos sobre alfabetização.Gosto muito de trabalhar por "agrupamento", por exemplo: Frutas - Animais- Cores - Meios de transportes, etc... E ao trabalhar cada grupo, 
trabalho frases, dinâmicas entre os estudantes... E sempre retomo o que foi ministrado. A alfabetização acontece pelo uso de imagens+sinal+nome.

P4. Trabalho com grupo de palavras e, à medida que elas são absorvidas, acrescento outras que fazem sentido, agregando os conteúdos de forma que estes estejam interligados para que se haja necessidade de recorrer ao grupo do léxico que já foi dado.

De acordo com as respostas das participantes, ainda que P1 tenha mencionado que o processo de alfabetização e letramento da criança surda ocorre de forma análoga a criança ouvinte, ao dizer que "acontece da "mesma forma" que acontece com os ouvintes", P1 demonstra ter uma boa concepção desse processo uma vez que relata a necessidade de o professor primeiro ensinar a Libras. Esse dado condiz com o que Sousa (2015) defende ao afirmar que a Libras é fundamental para mediar a aprendizagem da Língua Portuguesa. Além disso, a Libras propicia conhecimento de mundo aos seus falantes, aspecto essencial no processo de alfabetização e letramento de qualquer indivíduo. É importante destacar que, dentre as especificidades que envolvem o processo de alfabetização e letramento de crianças surdas, a aquisição da língua de sinais é um dos princípios da educação bilíngue para surdos enfatizados por autores como Fernandes (2006) e Sousa (2014).

Observamos que P2 e P3 também apresentam uma boa compreensão das peculiaridades concernentes à alfabetização e letramento da criança surda, ao apontarem o uso de material concreto e imagens como estratégia facilitadora desse processo. P3 demonstra entender que, conforme apontado por Fernandes (2006), diferente do que ocorre com a criança ouvinte, que há compatibilidade entre os sistemas de representação linguística, com a criança surda essa compatibilidade não acontece. Podemos inferir isso porque P3diz fazer uso primeiro de uma imagem, depois relaciona essa imagem a um sinal na Libras e, por fim, apresenta a palavra.

Ressaltamos a fala de P3 ao afirmar que precisamos "desconstruir" o que sabemos sobre alfabetização. Esse dado nos revela a necessidade de os cursos de formação inicial investirem mais na discussão sobre a alfabetização da criança surda. Além disso, P3 demonstra ter consciência de que o processo de alfabetização da criança surda não deve ocorrer da mesma forma daquele que estamos acostumados a trabalhar com a criança ouvinte. Logo, essa desconstrução passa por novas formas de pensar didática e 
metodologicamente falando. Esse dado é importante também porque a Língua Portuguesa geralmente é ensinada ao estudante surdo da mesma forma que ao ouvinte, desconsiderando-se as peculiaridades linguísticas comuns a essas pessoas. Acreditamos que P3 não recorre, por exemplo, as mesmas estratégias utilizadas para as crianças ouvintes. Estamos falando, nesse caso, em relação ao uso de atividades baseadas no som. Conforme foi apontado por Fernandes (2006) como sendo uma escolha errada, trazendo implicações sérias para a criança surda.

Na resposta de $\mathrm{P} 4$ não observamos clareza quanto à sua concepção desse processo. A sua resposta foi muito geral, não demonstrando especificidades relacionadas à educação de surdos. Ao afirmar: "Trabalho com grupo de palavras...", não ficou explícito, a exemplo de como ficou na fala de P3, se ela estava se referindo a campo semântico ou a lista de palavras.

A seguir, apresentaremos um quadro com o registro compilado das quatro observações feitas em sala de aula a respeito da dinâmica percebidas nas salas regulares bilíngues para surdos.

Quadro 1 - Síntese das observações com foco na dinâmica das salas regulares bilíngues para surdos.

\begin{tabular}{|c|c|c|c|c|c|c|c|c|c|c|c|c|c|c|c|c|}
\hline \multirow[t]{2}{*}{ Observações } & \multicolumn{4}{|c|}{ 19. Dia } & \multicolumn{4}{|c|}{ 2․ dia } & \multicolumn{4}{|c|}{ 3․ dia } & \multicolumn{4}{|c|}{ 4\%. dia } \\
\hline & S1 & S2 & S3 & S4 & S1 & S2 & S3 & S4 & S1 & S2 & S3 & S4 & S1 & S2 & S3 & S4 \\
\hline $\begin{array}{l}\text { Há utilização de } \\
\text { imagens e Libras. }\end{array}$ & $\mathrm{s}$ & $\mathrm{S}$ & $\mathrm{S}$ & $S$ & $\mathrm{~s}$ & $\mathrm{~S}$ & $S$ & $\mathrm{~S}$ & $S$ & $\mathrm{~S}$ & $\mathrm{~s}$ & $\mathrm{~S}$ & $\mathrm{~S}$ & $S$ & $S$ & $S$ \\
\hline $\begin{array}{l}\text { A professora faz } \\
\text { uso de teatro. }\end{array}$ & $\mathrm{s}$ & $\mathrm{N}$ & $\mathrm{S}$ & $\mathrm{S}$ & $\mathrm{s}$ & $N$ & $\mathrm{~S}$ & $\mathrm{~s}$ & $S$ & $N$ & $\mathrm{~S}$ & $\mathrm{~S}$ & $\mathrm{~S}$ & $\mathrm{~N}$ & $\mathrm{~S}$ & $\mathrm{~S}$ \\
\hline $\begin{array}{l}\text { A professora é } \\
\text { fluente em Libras. }\end{array}$ & $\mathrm{s}$ & $\mathrm{S}$ & $\mathrm{S}$ & $S$ & $\mathrm{~s}$ & $S$ & $S$ & $\mathrm{~s}$ & $S$ & $\mathrm{~s}$ & $\mathrm{~s}$ & $\mathrm{~s}$ & $\mathrm{~S}$ & $\mathrm{~s}$ & $S$ & $\mathrm{~s}$ \\
\hline $\begin{array}{l}\text { A Libras é usada } \\
\text { como língua de } \\
\text { instrução. }\end{array}$ & $\mathrm{s}$ & $\mathrm{S}$ & $S$ & $S$ & $\mathrm{~s}$ & $\mathrm{~S}$ & $\mathrm{~S}$ & $\mathrm{~s}$ & $S$ & $\mathrm{~s}$ & $\mathrm{~s}$ & $\mathrm{~s}$ & $\mathrm{~S}$ & $\mathrm{~s}$ & $\mathrm{~S}$ & $\mathrm{~S}$ \\
\hline $\begin{array}{l}\text { Há comunicação } \\
\text { efetiva entre os } \\
\text { estudantes e a } \\
\text { professora. }\end{array}$ & $\mathrm{s}$ & $\mathrm{S}$ & $\mathrm{S}$ & $S$ & $\mathrm{~S}$ & $\mathrm{~S}$ & $S$ & $\mathrm{~s}$ & $S$ & $\mathrm{~s}$ & $\mathrm{~s}$ & $\mathrm{~s}$ & $\mathrm{~S}$ & $\mathrm{~S}$ & $S$ & $\mathrm{~s}$ \\
\hline
\end{tabular}

Fonte: Wilma Pastor de Andrade Sousa, 2020.

Conforme registramos nas observações feitas em sala de aula, expostas no quadro 1 , todas as professoras voluntárias participantes deste estudo possibilitaram boa dinâmica em sala de aula. Elas consideraram a pessoa surda como ser visual, fazendo uso de imagens e da Libras, por exemplo, para facilitar a compreensão dos estudantes durante as aulas. A esse 
respeito, as estratégias de uso de imagens associadas a Libras, como elemento facilitador do ensino e aprendizagem de crianças surdas, são indicadas por autores como Sousa e Mourão (2018).

Na dinâmica de sala de aula, observamos também o uso de teatro. Esse recurso é muito importante e traz grande benefício para as pessoas surdas, em qualquer nível de aprendizagem, sobretudo para a criança que ainda não domina a língua de sinais, por lhe auxiliar na construção de conceitos. Apenas na S2 a professora não fez uso em nenhuma das quatro observações realizadas.

O fato de P1, P2, P3 e P4 serem fluentes em Libras, além de confirmar o que fora dito por elas por ocasião da entrevista, mostra-nos avanço na educação de surdos, visto que, um dos grandes obstáculos é a comunicação do estudante surdo com a professora em sala de aula. Nessas salas observadas, portanto, esse problema não foi constatado. Outro aspecto a ser considerado é o fato de todas as participantes utilizarem a Libras como língua de instrução, e não como recursos didático-metodológico. Esses dois pontos observados corroboram com o que está posto no Decreto no 28.587, de fevereiro de 2015 que criou as salas regulares bilíngues.

Por fim, durante as quatro observações feitas, verificamos a efetiva comunicação entre os estudantes e a professora de cada sala de aula observada. Mais uma vez em conformidade com o Decreto no $28.587 / 2015$,ao determinar que os professores que lecionam nessas salas devem apresentar domínio da Libras. Esse dado mostra ainda o quanto que a educação bilíngue favorece as pessoas surdas uma boa dinâmica em sala de aula, uma vez que, em o professor dominando a língua de sinais, não haverá barreira na comunicação. Logo, o processo de alfabetização e letramento desses sujeitos poderá ocorrer de forma menos traumática.

\section{Considerações finais}

Este estudo nos possibilitou conhecer melhor a realidade de quatro das sete salas regulares bilíngues, instaladas em diferentes escolas da rede municipal do Recife-PE. Diante de questionamentos constantes, tais como: quais são as principais dificuldades enfrentadas pelas professoras das salas regulares bilíngues? Qual é a concepção das professoras sobre o processo de alfabetização e letramento das crianças nessas salas? Como é a dinâmica 
durante as aulas nessas salas? Bem como, norteados por meio do objetivo principal deste texto que é discutir o processo de alfabetização e letramento em salas bilíngues para surdos, com base em uma análise realizada em salas regulares bilíngues para surdos, em escolas da rede municipal na cidade de Recife-PE.

Os dados revelam que, de modo geral, as professoras alfabetizadoras têm clareza de como ocorre o processo de alfabetização e letramento da criança surda e quais as intervenções a serem feitas para mediar esse processo. Além disso, elas têm concepções a respeito desse processo, alinhadas aos princípios da educação bilíngue para surdos, uma vez que a maioria delas considera a Libras fundamental como ponto de partida. Contudo, apesar do empenho desses professores em respeitar as especificidades linguísticas dos estudantes surdos, a falta de conhecimento da Libras pelas crianças surdas e a escassez de material didático acessível têm sido os principais obstáculos apontados pelas participantes das salas regulares bilíngues.

Outro empecilho observado e que tem se tornado um fator importante para a efetivação da educação bilíngue para o estudante surdo, é o fato de não haver ainda uma política no município que garanta o acesso desses estudantes a educação bilíngue a partir da creche, já que o Decreto que instituiu as salas regulares bilíngues só garante o acesso a partir de 4 anos de idade. Vale salientar que a oferta de ensino para essa faixa etária está condicionada, nesse documento, a apresentação de estrutura adequada. Este foi um ponto de fragilidade que encontramos e que tem sido discutido junto aos gestores e da comunidade surda para que o ingresso da criança surda à educação bilíngue possa ser garantido desde zero ano, para que a criança surda não tenha prejuízo quanto ao desenvolvimento de linguagem. Gostaríamos de mencionar que a coordenação das salas e toda a equipe técnica gestora têm sido sensíveis ao nosso retorno das pesquisas feitas nessas salas, visando a melhoria do ensino bilíngue ofertado a população surda nas escolas municipais do Recife.

Um dado importante a ser destacado é a constatação de que todas as professoras alfabetizadoras participantes deste estudo fazem uso da língua de sinais como língua de instrução. Contudo, embora elas sejam bilíngues em Libras e em Língua Portuguesa, existem outros fatores que interferem e são igualmente importantes para a efetivação de uma educação bilíngue de 
qualidade. Citamos como exemplos, a participação de surdos adultos na equipe pedagógica e a valorização da cultura surda no espaço escolar.

Em relação à dinâmica observada em sala de aula, ressaltamos a comunicação efetiva entre os estudantes e as professoras por meio do uso da Libras, isso mostra uma dinâmica de sala de aula que possibilita uma interação fundamental para que o estudante se sinta mais seguro durante o processo educacional. Destacamos também os recursos utilizados pelas professoras alfabetizadoras, como o uso de imagens e da estratégia do teatro como elementos facilitadores da compreensão de conceitos pelas crianças surdas. Portanto, exceto alguns aspectos que necessitam serem ajustados, o processo de alfabetização e letramento em salas regulares bilíngues para surdos está caminhando bem. Acreditamos que com a garantia do acesso das crianças surdas na Educação Infantil desde a creche, ou seja, os bebês e as crianças bem pequenas, o contato dessas crianças com os seus pares e com surdos adultos fluentes em Libras, além de professores bilíngues, teremos uma configuração de uma educação bilíngue que atenda melhor as expectativas das pessoas surdas e de toda a sua comunidade, fazendo valer os embates travados ao longo de todo esse percurso educacional.

\section{Referências}

BARDIN, L. Análise de conteúdo. Tradução: Luís Antero Reto, Augusto Pinheiro. São Paulo: Edições 70, 2016.

BRASIL. Ministério da Educação. Lei de Diretrizes e Bases da Educação Nacional. LDBN 9.394, de 20 de dezembro de 1996.

BRASIL. Ministério da Educação. Parâmetros curriculares nacionais para a educação infantil. Ministério de Educação e do Desporto, secretaria de Educação Fundamental. Brasília: MEC/SEF, 1998.

BRASIL. Ministério da Educação. Secretaria de Educação Especial. Lei №. 10.436, de 24 de abril de 2002. Dispõe sobre a Língua Brasileira de Sinais LIBRAS e dá outras providências. 
BRASIL. Ministério da Educação. Secretaria de Educação Especial. Decreto № 5.626 de 22 de dezembro de 2005.

BRASIL. Ministério da Educação. Educação infantil, saberes e práticas da inclusão: dificuldades de comunicação e sinalização: surdez. 4. Ed. Secretaria de Estado da Educação do Distrito Federal. SEESP/ MEC: Brasília, 2006. BRASIL. Ministério da Educação. Plano Nacional de Educação - Lei no 13.005/2014. Disponível em: http://pne.mec.gov.br/18-planos-subnacionaisde-educacao/543-plano-nacional-de-educacao-lei-n-13-005-2014. Acesso em: 02 jul. 2020.

BRASIL. Ministério da Educação. Secretaria da Educação Básica. Base Nacional Comum Curricular. Brasília, DF, 2017.

CABRAL, C. F. Formação de professores para a educação infantil: um estudo realizado em um curso normal superior. Dissertação (Mestrado) - Pósgraduação em Educação, Pontífica Universidade Católica de Minas Gerais, Belo Horizonte, 2005.

DECHANDT, S. B. A apropriação da escrita por crianças surdas. In: QUADROS, R. M. (Org.) Estudos Surdos I. Série Pesquisas. Petrópolis: Arara Azul, 2006.

FERNANDES, Sueli. Práticas de letramento na educação bilíngue para surdos. Curitiba: SEED, 2006.

KOBER, D. C. Práticas de letramento na Educação de Surdos. In: Educação para surdos: práticas e perspectivas (MOURA, M. C. de; VERGAMINI, S. A. A.; CAMPOS, S. R. L.). São Paulo: Santos Editora, 2008.

QUADROS, R. M.; SCHMIEDT, M. L. P. Ideias para ensinar português para alunos surdos. Brasília: MEC, SEESP, 2006.

RECIFE. Decreto no 28.587, de fevereiro de 2015. Institui as salas regulares bilíngues para surdos na Rede Municipal de Ensino do Recife. Disponível em: http://www.legisweb.com.br/legislacao/?id=281221. Acesso em: 02 jul. 2020. 
RECIFE. Instrução Normativa SEEDUC no 2 de janeiro de 2016. Dispõe sobre a normatização das Salas Regulares Bilíngues no Município do Recife para Estudantes Surdos e de outras providências. Disponível em:

https://www.normasbrasil.com.br/norma/instrucao-normativa-2-2016recife_315265.html. Acesso em: 02 jul. 2020.

SOUSA. W. P. A. Alfabetização de crianças surdas na perspectiva do letramento. In: Letramento e inclusão. PNAIC Paraíba. E. M. B. F. (Org.) Editora UFPB, 2014.

SOUSA. W. P. A. O ensino de língua portuguesa escrita para a pessoa surda no contexto da educação inclusiva. In: Temas em educação inclusiva: alteridade e práticas pedagógicas / NASCIMENTO, G. R. P.; DIAS JÚNIOR, J. F. (Orgs.). - Pipa Comunicação e Editora Universitária UFPE, 2015. 236p. 1. ed. ISBN 978-8566530-52-0

SOUSA. W. P. A. Práticas pedagógicas inclusivas com crianças surdas no contexto da creche. In: Didática e a prática de ensino na relação com a sociedade (Orgs.) SALES, J. A. M. [et al.] - Fortaleza: CE: EdUECE, 2015. (Coleção Práticas Educativas) Trabalhos apresentados no XVII ENDIPE Encontro Nacional de Didática e Prática de Ensino. Livro 3 03497. Disponível em: http://www.uece.br/endipe2014/ebooks/livro3/407\%20PR\%C3\%81TICAS \%20PEDAG\%C3\%93GICAS\%20INCLUSIVAS\%20COM\%20CRIAN\%C3\%87AS \%20SURDAS\%20NO\%20CONTEXTO\%20DA\%20CRECHE.pdf. Acesso em: 02 jul. 2020.

SOUSA. W. P. A.; MOURÃO, C.A. Práticas de letramento para crianças surdas no ciclo de alfabetização. In: LIMA; R. A.; CAVALCANTE, T. C. F.; SOUSA, W. P. A. (Orgs.). Práticas pedagógicas em educação inclusiva: compartilhando experiências. 2018, v. 01. Recife. Editora Universitária da UFPE, p. 23-37. ISBN 978-85-415-0999-2. 